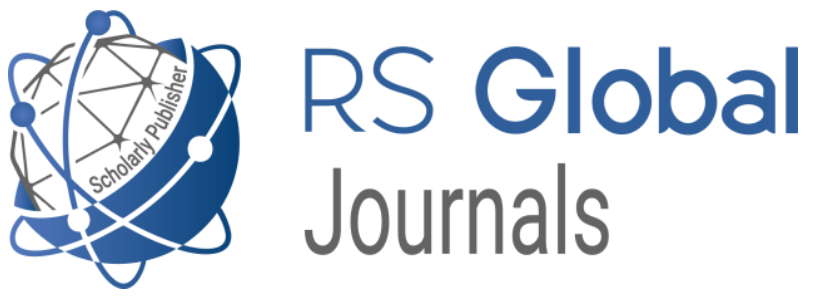

Scholarly Publisher

RS Global Sp. z O.O.

ISNI: 0000000484952390

Dolna 17, Warsaw, Poland 00-773

Tel: +48226022703

Email: editorial_office@rsglobal.pl

JOURNAL International Journal of Innovative Technologies in Social Science

p-ISSN

$2544-9338$

e-ISSN

2544-9435

PUBLISHER

RS Global Sp. z O.O., Poland

ARTICLE TITLE

IMPACT OF COLOUR SYMBOLISM ON ENGLISH COLOUR IDIOMS AND THEIR GEORGIAN EQUIVALENTS

$\operatorname{AUTHOR}(\mathbf{S})$

Nino Kemertelidze, Meri Giorgadze

Nino Kemertelidze, Meri Giorgadze. (2021) Impact of Colour

Symbolism on English Colour Idioms and their Georgian

ARTICLE INFO

Equivalents. International Journal of Innovative Technologies in Social Science. 1(29).

doi: 10.31435/rsglobal_ijitss/30032021/7453

DOI

https://doi.org/10.31435/rsglobal_ijitss/30032021/7453

RECEIVED

20 December 2020

ACCEPTED

12 February 2021

PUBLISHED

17 February 2021

LICENSE

This work is licensed under a Creative Commons Attribution

4.0 International License.

(C) The author(s) 2021. This publication is an open access article. 


\title{
IMPACT OF COLOUR SYMBOLISM ON ENGLISH COLOUR IDIOMS AND THEIR GEORGIAN EQUIVALENTS
}

\author{
Nino Kemertelidze, Professor, Lecturer of English Language at Georgian Technical University, Tbilisi, \\ Georgia
}

Meri Giorgadze, PhD, Lecturer of English Language at Tbilisi State University, Tbilisi, Georgia

DOI: https://doi.org/10.31435/rsglobal_ijitss/30032021/7453

\section{ARTICLE INFO}

Received 20 December 2020

Accepted 12 February 2021

Published 17 February 2021

\section{KEYWORDS}

Colour idioms, idiomatic expressions, symbolic meaning, loading, Georgian equivalent, collocation, connotation.

\begin{abstract}
The presented article aims to study colour idioms; to be more precise, idioms one element of which is a colour designating word. During the research, we were interested in identifying whether the symbolic loading of certain colours has an impact on the meaning of an idiom. The conducted research revealed that colour symbolism greatly influences the meaning of colour idioms in the English language. More specifically, it conditions the implication of the whole idiomatic phrase. While conducting the research, we studied about 200 colour idioms in the English language and tried to find out their Georgian equivalents. It appeared that 94 idioms did not have the corresponding Georgian versions on the etic level. Consequently, 106 ones had the corresponding Georgian translations, out of which 30 phrases were transferred into the Georgian language as idiomatic expressions and colour was maintained only in 17 of them. Besides, it is noteworthy that one and the same colour can have different symbolic loadings what is vividly seen in the presented work.
\end{abstract}

Citation: Nino Kemertelidze, Meri Giorgadze. (2021) Impact of Colour Symbolism on English Colour Idioms and their Georgian Equivalents. International Journal of Innovative Technologies in Social Science. 1(29). doi: 10.31435/rsglobal_ijitss/30032021/7453

Copyright: (C) 2021 Nino Kemertelidze, Meri Giorgadze. This is an open-access article distributed under the terms of the Creative Commons Attribution License (CC BY). The use, distribution or reproduction in other forums is permitted, provided the original author(s) or licensor are credited and that the original publication in this journal is cited, in accordance with accepted academic practice. No use, distribution or reproduction is permitted which does not comply with these terms.

Introduction. An idiom is a phrase that reveals in its syntactic and semantic structure the specific and unique properties of a given word. They are characterized as a kind of reflection of the peculiarities of culture, natural living conditions, uniqueness of the national character and also as an integral part of a language.

Idioms are unmotivated and non-derivative combinations of words, in the meaning of which there is no relation with the meanings of its components. Unpredictability of meanings is the main characteristic feature of an idiom. Thus, it is a fixed collocation, the meaning of which has been fully or partially reconsidered, i.e. it does not correspond to the sum of the literal meanings of its constituent elements.

Idioms give a text shade of meanings and enhance the verbal impact of senders on recipients of the information. They can significantly enrich the communication process and eliminate unnecessary formality.

Idioms can be called an integral part of a language since they are met in any area of everyday life. They are closely related to the culture of the country and the world image of a particular nation.

A lot of things can be said about idioms, but the presented article aims at discussing colour idioms; to be more precise, idioms one element of which is a colour designating word. While conducting the research, we were interested to find out whether the symbolic loading of this or that colour has an impact on the meaning of an idiom. For this reason, we studied about 200 idiomatic phrases out of which 23 examples are discussed in the presented article. 
Symbolic impact on colour idioms. Different linguists discuss the notion symbol in different ways. Some believe that symbolism exists only in poetry where it fully realizes its mechanisms. Notwithstanding this, symbols function also beyond poetics, namely in language. There are various types of symbols, like historical symbols, language symbols that express certain social phenomena, facts. They can also be found in gestures and colours. It is notable that one and the same colour can have different symbolic loadings. Moreover, different languages, different nations perceive colour symbolism in different ways.

White. Differentiation of various colours is the result of the emotional meaning of coloured things in the language. Once, white, bright, light and shining were inseparable concepts; they even overlapped each other [7]. The meaning of the word white mainly depended on the emotional meaning of colour reflective items. As light opens the visual world, it became a symbol of life and mental capabilities of a human. From the very beginning, the symbolic meaning of the words white and bright referred to skin, hair and eyes. Earlier, the word bright did not indicate a human's high intellect as it does today (e.g. a bright man). It indicated health, happiness, vitality, and even holiness. Consequently, it is considered that healthy, holly and wholesome are interrelated concepts. While bright and radiant express vitality of a person, pale-white is a symptomatic reaction of skin to illness, oldness, and even death. That is why W. Shakespeare writes in his comedy "All Is Well That Ends Well" - Let the white death sit on thy cheek forever.

Thus, the colour white has contradictory symbolic meanings. On the one hand, it symbolizes purity having a positive connotation, and on the other hand - death, severity with a negative connotation. But, the research showed that as a component of an idiomatic expression, this colour acquires other symbolic loadings as well.

The idiom white elephant in the Georgian language is translated as ogono bзом⿻ [Tetri sp'ilo]. It is a literal translation. In both languages, they have the same meaning - something of little or no value; something that has cost a lot of money but has no useful purpose. We do not have to forget that white elephants do not exist in reality. Actually, elephants that are lighter in colour than normal are called white elephants. Thus, the given English idiom in the Georgian language is rendered also with an idiom and the colour is maintained. It is noteworthy that in the described case, the colour white has a negative connotation. The latter can probably be explained by the etymology of the phrase. According to the etymology, "in Siam, elephants were working animals. However, white elephants were considered sacred and therefore were not to be put to work. The owner was then left to feed the elephant but could get no work from it. It is said that the King of Siam used to make a present of a white elephant to courtiers he wanted to ruin" [11].

The above mentioned is well revealed in Ernest Hemingway's short story "Hills Like White Elephants". If not the idiomatic meaning of the phrase (white elephant) the whole text would be vague and difficult to comprehend.

The idiomatic expression white trash is a very informal phrase. It is definitely a derogatory expression that originally comes from South America. According to the etymology, it first appeared in 1850. Black slaves in the Southern United States called white people white trash and thus openly demonstrated their contempt [6]. This explains the negative connotation of the word white in the given idiom. Alongside the change of history, the discussed expression acquired a bit different meaning. It is still offensive but certainly is not used by slaves. Its present meaning is as follows: an offensive way of describing poor white people who are not educated. In the Georgian language, the phrase does not

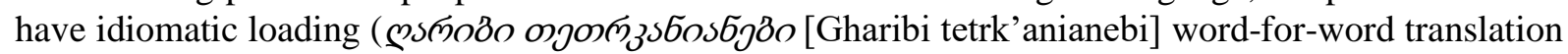
- poor white men), though the colour white is still found in its Georgian version.

The idiom whiter than white (one who is completely good and honest and never does anything bad) is probably based on the symbolic meaning of the colour white which is associated with purity, everything good and right. The phrase first appeared in W. Shakespeare's poet Venus and Adonis.

Who sees his true-love in her naked bed,

Teaching the sheets a whiter hue than white;

But when his glutton eye so full hath fed,

His other agents aim at like delight?

In the Georgian language, we do not come across the corresponding idiomatic equivalent. It is noteworthy that the idiom whiter than white given in Shakespeare's poem in Georgian is translated with

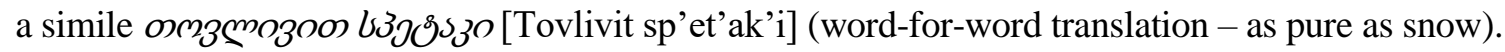


The idiomatic phrase white-livered describes a cowardly person who is afraid of almost everything. It can be supposed that the so-called symbolic loading of the word liver was taken into consideration while coining the idiom. To be more precise, liver is the source of life, passion, or emotion. According to Greek mythology, the ancient Greeks used to sacrifice an animal before the battle. The liver was the main defining sign - if it was red, then all was fine, but if it was pale it lost its functions. Namely this fact caused the formation of the idiom white-livered. That is the reason why the colour white attains a negative connotation. As far as our research shows, the corresponding idiomatic expression does not exist in the Georgian language.

The idiomatic expression to bleed somebody white means leaving somebody without money. As it is known, the term dates back from the seventeenth century and is associated with gamblers. According to the saying, once a victim was made to pay through the nose (lost all one's blood through the nose, otherwise saying bled white). As losing blood causes paleness, the word white was used while

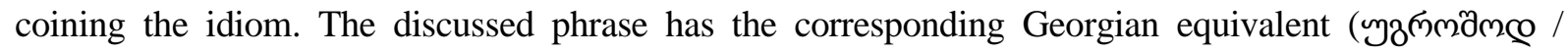

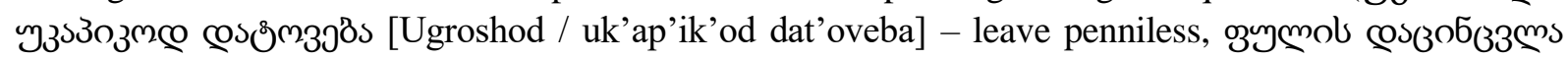
[Pulis datsintsvla] - swindle out of money), but in Georgian it is not an idiomatic expression.

The idiomatic phrase white man (an honest, honourable man) with its etymology and symbolic meaning of the colour white is similar to the idiom whiter than white, but the latter is more poetic and causes more emotions. During the investigation, we were not able to find its corresponding Georgian equivalent.

Black. Another colour to be discussed is black. It is scientifically confirmed that white and black are achromatic colours. The black colour is inseparable with the concepts dark and deep. Absence of light is perceived as depth or something that covers the source of light. W. Shakespeare meant an abyss without light when he wrote in his tragedy "Macbeth" My black and deep desires.

Thus, black colour is associated with death, dirt, and villainy.

The idiomatic phrase black sheep means an odd or bad member of a group or a family, unlike the others. It is very easy to understand the etymology of this expression. It is a well-known fact that sheep mostly are of white colour and one can hardly ever find a black sheep in its nominative meaning. Consequently, the mentioned collocation acquires the meaning of something that is different from others. Thus, the negative loading of the colour black conditions the meaning of the whole idiomatic expression. In the Georgian language, the phrase is translated as mzsbol zyds

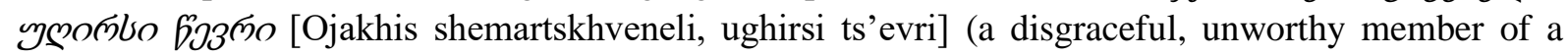
family) which is not an idiom at all and the Georgian phrase includes no colour.

The idiom to be in a black mood means to be irritable, angry, or even depressed. As in the above case, it is exactly symbolism that should be minded while understanding this phrase. It is noteworthy that on the etic level we were not able to find a Georgian equivalent of this idiom but

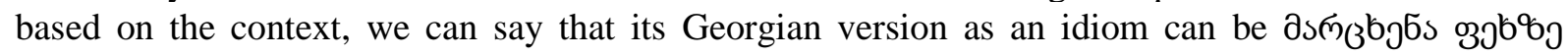
sৎ̧mдs [Martskhena pekhze adgoma] (word-for-word translation - to get out of bed on the left foot). Though, in the dictionary, this Georgian phrase is translated as "to get out of bed on the wrong side".

It seems that this colour should always have a negative connotation. But the conducted research showed that this is not always the case. The example discussed below proves the mentioned though it concerns only the financial sphere.

The idiomatic phrase to be in the black can be understood as to be successful or profitable and definitely has a positive connotation. It should be mentioned that the meaning of this idiom is conditioned by the activity conducted in business, namely bookkeeping. It is a matter of common knowledge that when a company has a net profit after considering all expenses, it is marked in black ink, unlike the loss that is marked in red ink. In the Georgian language, it is translated with an ordinary phrase bsfaols

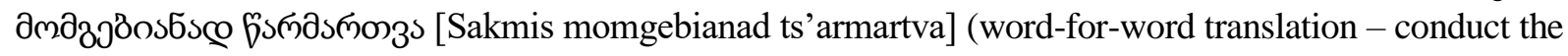
business profitably) which has nothing to do with an idiom, and colour is not included.

Gray. The intermediary colour between white and black is gray. It occupies a central place not only between solid colours, but also in psychological reality. There is no absolute white and absolute black. In reality, we perceive a thing somewhere between black and white depending on the background. The main symbolic meaning of gray is dullness; it is also associated with old age (gray hair). It can be supposed that due to the decolouration of skin, this colour acquires another symbolic meaning. It should be mentioned that we do not say gray skin; instead of it, we use the word pale. As an emotional reaction, paleness can be caused by fear or illness. Exactly this fact conditions the meaning of the idiomatic phrase discussed below. 
The idiom to get/have gray hair from indicates that someone is very worried or upset. Similarly, the idiom to give gray hair to means to worry, bother someone. Unfortunately, in the Georgian language, we were not able to find their equivalents.

Yellow. Symbolism is vividly observed in yellow and green colours. They even may be called overflowing. Sometimes a green colour is perceived as yellowish and vice versa. There are also such colours as greenish-yellow and yellowish-green. In the English language as in many other languages yellow and yolk are cognate words. It should be noted that different things seldom achieve the tint of the colour of the ripe lemon. On the other hand, bile secretion sometimes can be perceived as yellow and bitter at the same time. Such words make us think that the yellow colour is associated with bitterness, envy, jealousy, and fear. It should be mentioned that bile can be not only yellow but also green. That is why the symbolic loading of these two colours in some contexts coincide, as they are close to each other. In such cases, green indicates oldness, anemia which is called green sickness. Jealousy is also symbolized by both colours and the colour yellow also symbolizes cowardice [7].

The idiomatic phrase yellow dog refers to a despicable person or a worthless thing. Probably this meaning was taken into consideration when the British writer Martin Amis named his novel "Yellow Dog" underlying the main character's personality who was a gangster. Thus, the mentioned colour is used in a derogatory sense. Though according to the origin, dogs are called yellow because of their yellow coats and Merriam-Webster Dictionary says that "this usage probably came about from the traditional association of the colour yellow with cowardice" [12], we think that the mentioned idiomatic phrase is associated with one of the symbolic meanings of this colour - bitterness and not cowardice. As the meaning of this expression is a despicable person, we believe that cowardice and despicableness cannot be identified. A person can be cowardly but not despicable and vice versa. Unfortunately, during the research, we were not able to find the Georgian equivalent of this expression.

It is noteworthy that adding one more word to a certain idiomatic phrase changes its meaning. A vivid example of this is the idiomatic expression yellow dog contract which means an employment contract in which a worker disavows membership in and agrees not to join a labour union in order to get a job. Thus, the sense of the aforementioned phrase yellow dog is changed and its meaning is associated with another symbolic loading of the colour yellow, namely cowardice. The Georgian equivalent of this idiom is

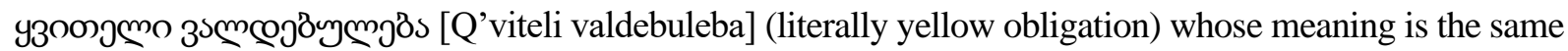
as in English. So, the mentioned idiomatic phrase in the Georgian language is rendered with an idiom and the colour yellow is maintained though, the modified word is different. It should also be noted that the number of constituent elements of this phrase differs in the English and Georgian languages (English - adj $+\mathrm{n}+\mathrm{n}$; Georgian $-\operatorname{adj}+\mathrm{n}$ ). As we see, the word $d o g$ is lost in the Georgian equivalent.

Thus, if we compare the discussed idioms yellow dog and yellow dog contract, it becomes apparent that one and the same idiom can change its meaning and consequently, symbolic loading by adding another word.

The meaning of the idiomatic expression yellow dirt is gold. It is a very interesting case to discuss. We suppose that this collocation acquired its meaning not because of colour, but owing to the second component of the phrase, namely dirt. If we go deep into our consideration, we will come to the conclusion that the mentioned phrase got its meaning because of the word dirt. We think that in this case gold (the meaning of the idiom) is associated with a coin, i.e. money, and money is considered to be filthy. In this case, namely the second component of the expression conditions its idiomatic meaning, and the colour yellow is used in its nominative meaning as gold is yellow itself. In the Georgian language, the phrase is rendered with only one word $m g$ mo [okro](gold) which is not an idiom at all.

Green. While studying the material under investigation, we came across a very interesting case of idioms with the colour green. In this case, one of the symbolic meanings of this colour jealousy/envy - has an impact on the process of coining idioms.

The idiomatic expression to look through green glasses means to be jealous or envious of somebody. It is noteworthy that the word-combination green glass included in the mentioned phrase is not an idiom at all. It simply means the colour of glass. Only the whole phrase is considered to be an idiom. We were not able to find its Georgian equivalent. But its synonymous idiomatic expression

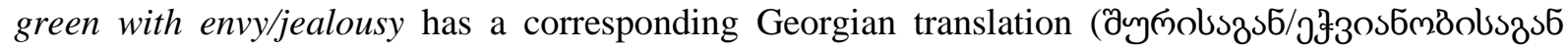

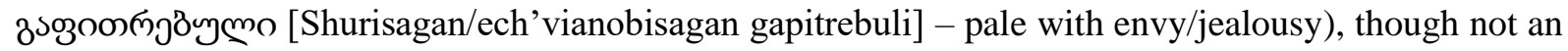
idiom. Thus, green is associated with jealousy [10].

Based on the mentioned idioms, W. Shakespeare coined very interesting idiomatic expressions - green-eyed monster and green-eyed jealousy. 
Beware, my lord, of jealousy; it is the green-eyed monster which doth mock the meat it feeds on.

(Othello)

How all the other passions fleet to air, As doubtful thoughts, and rash-embraced despair, And shuddering fear, and green-eyed jealousy! (Merchant of Venice)

In the Georgian language both phrases sound as follows:

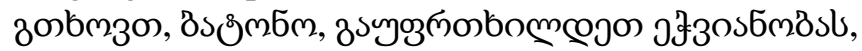

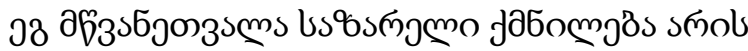

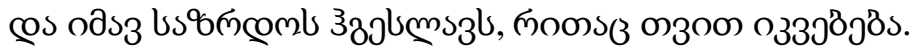

$$
\begin{aligned}
& \text { (लоீ๐mm) }
\end{aligned}
$$

[Gtkhovt, bat'ono, gauprtkhildet ech'vianobas, eg mts'vanetvala sazareli kmnileba aris da imav sazrdos hgeslavs, ritats tvit ik'vebeba

$$
\text { (ot'elo)] }
$$

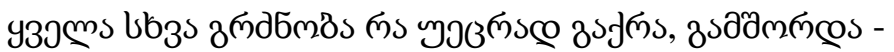

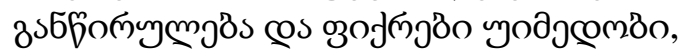

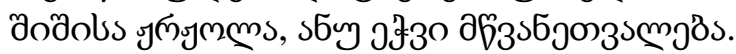

$$
\begin{aligned}
& \text { ( }
\end{aligned}
$$

[Q'vela skhva grdznoba ra uetsrad gakra, gamshorda gants'iruleba da pikrebi uimedobi, shishisa zhrzhola, anu ech'vi mts'vanetvaleba

(venetsieli vach'ari)]

In both examples, jealousy is characterized as green-eyed. While making these idiomatic expressions the symbolic meaning of the colour green - jealousy - plays not the last role. It should be interesting to note that "green and pale were alternate meanings of the same Greek word. In the seventh century B.C., the poetess Sappho used the word green to describe the complexion of a stricken lover. The Greeks believed that jealousy was accompanied by an overproduction of bile, lending a pallid green cast to the victim. Ovid, Chaucer, and Shakespeare followed suit, freely using green to denote jealousy or envy" [9].

The idiomatic expression put more green into something means to spend more or to increase investment in it. To understand the mentioned idiom, we have to take into consideration the fact that green is the most transparent colour due to its phonemic relation with the word to grow. Thus, besides the aforementioned symbolic loadings, green also symbolizes growth, development, youth, optimism. The Georgian equivalent of this idiom was not found.

Blue. The next colour to discuss is blue. It is a very interesting colour from the point of view of its symbolic loading and idiomatic expressions. Things with blue colour, blue tint were known earlier than the general term for the colour blue appeared. At first, the English word blue meant livid. Blue, first of all, is the colour of eyes, the sea, and the sky. The symbolic function of this colour raises psychological issues. Blue is considered to be cold colour, decolouration of skin in cold weather and especially after death. Shakespeare uses this colour as the colour of truth when he writes "Lie all manner of colours but blue" [13].

It is also considered that the colour blue has irreal characteristics that describe depression without any reason. That is why, this colour is the symbol of melancholy, sadness (I am blue, I feel blue, etc.) [7].

The idiomatic expression blue funk means a state of extreme nervousness or despair. This phrase leads us to a very interesting case. The word funk itself means a state of paralyzing fear; a depressed state of mind. At the first glance, if we say simply he is in funk, it will be clear that a person is afraid of something or is in depression, but the word blue with its symbolic loading (melancholy, depression) intensifies the meaning of the whole phrase. The Georgian equivalent of this idiom was not found while conduction the research.

The idiomatic phrase bolt from the blue is very impressive. It means something that you do not expect to happen and that surprises you very much. It can have both positive and negative connotations depending on the context. The word bolt means a lightning stroke and the whole idiomatic meaning is based on one of the symbolic meanings of the colour blue - association with the 
sky. Due to the fact that lightning is not anticipated to appear in good weather, i.e. when the sky is cloudless and happening so surprises us, the phrase is connected with unexpectedness.

The same can be said about the idiom out of the blue which is a synonym of the abovedescribed phrase.

It is worth paying special attention to the Georgian equivalents of these idioms. As it has been mentioned, bolt from the blue/out of the blue can be used both in positive and in negative senses. In the Georgian language, they are translated with three phrases: дмэлммсобјмо ylos usiamovneba] (unexpected unpleasantness); ylos surprise); ajbozoon cosj(3 oşb [Mekhivit daetsa tavs] (it struck him/her like a thunder). Unlike the English idioms, all three Georgian phrases have negative connotations. Moreover, only the third Georgian equivalent appears to be a simile though, the colour blue does not dominate in the Georgian translation.

The idiom by all that is blue (to swear by everything in the world) serves as one more example of the symbolic association of blue with the sky. In addition to the previous examples, this case also emphasizes the symbolic loading of the sky - infinity. To understand the mentioned idiom, we have to mind that blue is associated with the sky and the sky with infinity. In the Georgian language, this expression is presented with an ordinary collocation y39mso3jøl $393 \circ 3980$ [Q'velapers gepitsebi] (literally - I swear by everything) and not as an idiom, where blue is not mentioned.

Red. The colour red occupies a vivid place among other colours. It is the most widespread, ancient term. It comes from the colour scarlet and is spread up to bright crimson, orange and brown. Red has a wide range of symbolic loading such as life, hope, courage, health, love, anger, vigour, heat, heated emotions, optimism. For instance, the symbolic meaning of the phrase red rose is associated with the red colour of blood. There is even a saying "Black Rose Is an Emblem of Sorrow, Red Rose Is an Emblem of Love".

The idiomatic phrase to see the red mist means to lose temper and self-control completely. It seems that the meaning of the idiom is based on one of the symbolic meanings of red - anger. The phrase definitely has a negative connotation. While conducting the research, we were not able to find its Georgian equivalent.

In the example discussed below the same colour reveals a positive connotation. The idiom to paint the town red is defined as to have a great time, party. It might be associated with the colour of fireworks that are shot and bonfires that are lit to celebrate something. In the Georgian language, the

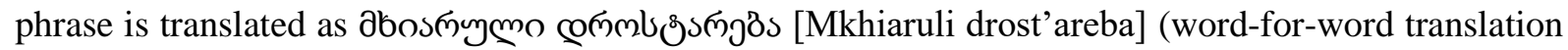
- fun pastime) which has nothing to do with idioms.

Conclusions. Thus, the conducted research revealed that colour symbolism has a great impact on the meaning of English colour idioms. To be more precise, it conditions the implication of the whole idiomatic phrase. As it has already been mentioned, we studied about 200 idiomatic expressions in which one component was a colour designating word and tried to find out their Georgian equivalents. It appeared that 94 idioms did not have the corresponding Georgian versions on the etic level. Consequently, 106 ones had the corresponding Georgian translations, out of which 30 phrases were transferred into the Georgian language as idiomatic expressions and colour was maintained only in 17 of them. It should also be emphasized that one and the same colour can have different symbolic loadings. Moreover, different languages, different nations perceive colour symbolism in different ways.

\section{REFERENCES}

1. Alousque I. N. (2011). "A Semantic and Pragmatic Analysis of English Colour Idioms". Babel-Afial, N 20. Spain, pp. 149-162.

2. Ayto, J. (2010). Oxford Dictionary of Idioms. Oxford University Press. Third edition.

3. Bu, J. (2018). Class-Book of Comparative Idioms: English - French. Sagwan Press, 162 p.

4. Collins English Dictionary. (2011). Collins; 11th Revised edition.

5. Dąbrowska, A. (2019). A Syntactic Study of Idioms. Cambridge Scholars Publishing. UK, 372 p.

6. Isenberg, N. (2016). White Trash: The 400-year Untold History of Class in America. New York: Penguin, 496 p.

7. Kemertelidze, N. (1994). Adverbial Attributes as Epithet. Tbilisi, Publishing-house "Metsniereba", 162 p.

8. Kemertelidze N., Giorgadze M. (2020). "One Approach to Idioms and Their Peculiarities in the English Language". European Scientific Journal, Vol.16, No.11, pp. 13-28.

9. Neman, J., Silver, C. (1999). The Wordsworth Book of Euphemism, Wordsworth Editions Ltd. UK, 371 p.

10. Ogarkova, A. (2007). "Green-Eyed Monsters: A Corpus-Based Study of Metaphoric Conceptualizations of JEALOUSY and ENVY in Modern English". Metaphorik.de 13. Kyiv, pp. 87-149.

11. Retrieved from https://en.wiktionary.org/wiki/white_elephant

12. Retrieved from https://www.merriam-webster.com/words-at-play/word-histories-related-to-dogs/bulldog-edition

13. Retrieved from https://archive.org/stream/b24854268/b24854268_djvu.txt 